\section{Optimal Spatial and Temporal Measurement Repetition for Selection in Japanese Persimmon Breeding}

\author{
M. Yamada', H. Yamane, and K. Yoshinaga ${ }^{2}$ \\ Akitsu Branch, Fruit Tree Research Station, Ministry of Agriculture, Forestry, \\ and Fisheries, Akitsu, Hiroshima 729-24, Japan
}

Y. Ukai

Faculty of Agriculture, University of Tokyo, Bunkyo-ku, Tokyo 113, Japan

Additional index words. Diospyros kaki, fruit breeding, environmental variance

Abstract Genetic and environmental variances for fruit ripening time (FRT), fruit weight, and soluble solids concentration (SSC) in Japanese persimmon (Diospyros kaki Thunb.) were estimated. The variance among fruit within a tree was the largest among environmental variances. Therefore, using a large sample size per tree and per year effectively increased heritability, but the effect was minimal when more than five fruit were sampled. The variance among years was largest for SSC and smallest for FRT. Generally, the variance associated with the genotype $\times$ year interaction was as large as the tree $\times$ year interaction. The variance among trees within a genotype was negligible for all traits. Repeating measurements yearly was more efficient than replicating trees.

In plant breeding, many seedlings must be tested to increase the chance of getting desirable genotypes. However, the number of seedlings used in fruit tree breeding is more restricted than in annual crop breeding, since fruit trees are large and occupy a large area. Success rate and cost are almost directly related to the space the progenies occupy and the amount of time they occupy that space (Hansche, 1983). Evaluating and selecting seedlings early decreases generation time and increases the scale of breeding work.

Most commercially important fruit traits, such as fruit ripening time (FRT) and fruit weight $(\mathrm{FW})$, are quantitative, and their performance fluctuates due to environmental factors. Therefore, it is important to obtain information on the contribution of genetic and environmental factors to phenotypic expression of such traits (Hansche and Beres, 1966; Hansche and Brooks, 1965; Machida and Kozaki, 1975; Yamada and Kurihara, 1984; Yamada et al., 1986).

Increasing the number of tree replications, years, and fruit samples would increase measurement accuracy. Estimated genetic and environmental variances for fruit traits could provide the optimal sample size, yearly repetition, or replication number to effectively dis-

Received for publication 12 May 1992. Accepted for publication 8 Feb. 1993. This paper is contribution E-154 of the Fruit Tree Research Station. The cost of publishing this paper was defrayed in part by the payment of page charges. Under postal regulations, this paper therefore must be hereby marked advertisement solely to indicate this fact.

'Current address: Okinawa Branch, Tropical Agriculture Research Center, Ministry of Agriculture, Forestry, and Fisheries, Kawarabaru 1091-1, Maezato, Ishigaki, Okinawa 907, Japan.

${ }^{2}$ Current address: Kuchinotsu Branch, Fruit Tree Research Station, Kuchinotsu, Nagasaki 859-25, Japan. criminate genetic differences for traits.

Reports on crops other than fruit (Kaltsikes, 1970; Mycroft, 1983; Patterson et al., 1977; Rasmussen and Lambert, 1961; Sekioka and Lauer, 1970; Shorter and Norman, 1983; Swallow and Wehner, 1989) indicated that adding more locations, years, or both was more efficient than adding replications.

The aim of this study was to estimate genetic and environmental variances for three fruit traits in Japanese persimmon and to provide the optimal sample size, yearly repetition, or number of tree replications to obtain the highest efficiency for evaluating genetic differences.

These investigations were conducted at the Fruit Tree Research Station, Akitsu, Japan, using genotypes of pollination-constant (Hume, 1914) and nonastringent Japanese persimmons. The trees used for the experiment were 15 years old in 1982 .

Variance estimation with 2 years, eight genotypes, and three trees. In a study with three trees each of eight genotypes, one branch with 25 to 148 fruit was sampled per tree. Fruit per genotype for 2 years

${ }^{2}$ Fruit weight was logarithmically transformed. were harvested at their respective FRT, which was when the fruit were ready to eat. FRT was judged by flesh firmness rated on a scale of 1 to 8 . A rating of $1=$ late September, $2=$ early October, 3 = mid-October, $4=$ late October, 5 $=$ early November, $6=$ mid-November, $7=$ late November, and $8=$ early December. FW and soluble solids concentration (SSC) also were evaluated. SSC was determined with a calibrated refractometer (model N1; Atago, Tokyo) on a small volume of fruit juice pressed out from the equatorial portion of fruit.

The measurements from the same number (25) of fruit taken randomly from each branch were subjected to analysis of variance as noted below. Before analysis, FW was log-transformed to improve the normality of the distribution of the observations. The genetic model adopted here for expressing the phenotypic value of a trait is $P_{i j k l}=\mu+g_{i}+t_{i j}+f_{i j k l}+y_{1}+$ $(\text { gy })_{i 1}+(\text { ty })_{i j 1}$, where $P_{i, k l}$ is the phenotypic value of the kth fruit of the jth tree of the ith genotype in the lth year, $\mu$ is the overall mean, $\mathrm{g}$, is a random effect contributed by the ith genotype, $t_{i j}$ is a random effect of the jth tree of the ith genotype, $y_{1}$ is a random effect of the lth year, $f_{i j k}$ is a random effect of the kth fruit of the jth tree of the ith genotype in the lth year, $(\mathrm{gy})_{\mathrm{il}}$, is the interaction between the ith genotype and the lth year, and (ty $)_{\mathrm{ij} 1}$ is the interaction between the jth tree of the ith genotype and the lth year.

Total variance $\left(\sigma_{\mathrm{T}}^{2}\right)$ in the analysis of variance was divided into the variance associated with genotype $\left(\sigma_{g}^{2}\right)$ trees within genotype $\left(\sigma_{t}^{2}\right)$, fruit samples within a tree $\left(\sigma_{\mathrm{f}}^{2}\right)$, year $\left(\sigma_{\mathrm{v}}^{2}\right)$, the genotype $\times$ year interaction $\left(\sigma_{\mathrm{g}}^{2}\right)$, and the tree $x$ year interaction $\left(\sigma_{t y}^{2}\right)$.

As the result of analysis of variance, the effects of genotype, year, the genotype $\mathrm{x}$ year interaction, and the tree $\mathrm{x}$ year interaction were significant at $P \leq 0.01$ for all three fruit traits, with the exception of year and genotype $x$ year interaction for FRT, for which the year effect was very small ( Table 1). The effect of tree within genotype was nonsignificant for all traits. The ratio of the genetic variance to the total variance was highest for FRT and lowest for SSC (Table 2).

The contribution of spatial environmental variance components $\left(\sigma_{t}^{2}, \sigma_{t,}^{2}, \sigma_{f}^{2}\right)$ to $\sigma_{T}^{2} v a s$ similar among fruit traits. Among trees, $\sigma_{t}^{2}$ was negligibly small. The $\boldsymbol{\sigma}_{\mathrm{f}}^{2}$ was largest among

Table 1. Analysis of variance for fruit traits of Japanese persimmon using eight genotypes with three trees

\begin{tabular}{|c|c|c|c|c|c|}
\hline \multirow[b]{2}{*}{$\begin{array}{l}\text { Source of } \\
\text { variation }\end{array}$} & \multirow[b]{2}{*}{$\mathrm{df}$} & \multicolumn{3}{|c|}{ Fruit trait (mean square) } & \multirow[b]{2}{*}{ Expected mean squares } \\
\hline & & $\begin{array}{l}\text { Fruit } \\
\text { ripening } \\
\text { time }\end{array}$ & $\begin{array}{c}\text { Fruit } \\
\text { wt }^{\mathbf{z}} \\
\left(\times 10^{-3}\right)\end{array}$ & $\begin{array}{l}\text { Soluble } \\
\text { solids } \\
\text { concn }\end{array}$ & \\
\hline Genotype & 7 & $501.48^{* * *}$ & $12.52^{* *}$ & $155.92^{* *}$ & $\sigma_{f}^{2}+25 \sigma^{2}+75 \sigma_{\mathrm{g}}^{2}+50 \sigma^{2}+150 \sigma^{2}$ \\
\hline Year & 1 & $16.05^{\mathrm{NS}}$ & $10.52^{* *}$ & $761.02^{* *}$ & $\sigma_{\mathrm{f}}^{2}+25 \sigma_{\mathrm{ty}}^{2}+75 \sigma_{\mathrm{gy}}^{2}+600 \sigma_{\mathrm{y}}^{2}$ \\
\hline Genotype & & & & & \\
\hline$x$ year & 7 & $9.43^{\mathrm{Ns}}$ & $1.20^{* *}$ & $80.65^{\mathrm{Ns}}$ & $\sigma_{\mathrm{f}}^{2}+25 \sigma_{\mathrm{ty}}^{2}+75 \sigma_{\mathrm{gy}}^{2}$ \\
\hline $\begin{array}{l}\text { Among trees } \\
\text { within genotype }\end{array}$ & 16 & $3.59^{\mathrm{Ns}}$ & $0.23^{\mathrm{Ns}}$ & $8.92^{\mathrm{Ns}}$ & $\sigma_{f}^{2}+25 \sigma_{v}^{2}+50 \sigma_{t}^{2}$ \\
\hline $\begin{array}{l}\text { Tree } \times \text { year } \\
\text { Among fruit }\end{array}$ & 16 & $4.18^{* *}$ & $0.16^{* *}$ & $5.96^{* *}$ & $\sigma_{f}^{2}+25 \sigma_{t y}^{2}$ \\
\hline within tree & 1152 & 0.49 & 0.04 & 1.70 & $\sigma_{\mathrm{f}}^{2}$ \\
\hline
\end{tabular}

${ }_{\text {ss, }, * *}^{*}$ Nonsignificant or significant at $P \leq 001$, respectively, using F test. 
Table 2. Estimates of variance components and their percentage to total variance obtained from the analysis of variance for Japanese persimmon fruit traits using eight genotypes with three trees per genotype for 2 years.

\begin{tabular}{|c|c|c|c|}
\hline \multirow[b]{2}{*}{$\begin{array}{l}\text { Variance } \\
\text { components }\end{array}$} & \multicolumn{3}{|c|}{ Fruit trait (mean square) } \\
\hline & $\begin{array}{c}\text { Fruit } \\
\text { ripening } \\
\text { time }\end{array}$ & $\begin{array}{c}\text { Fruit } \\
\text { wt }^{\mathrm{z}} \\
\left(\times 10^{-5}\right) \\
\end{array}$ & $\begin{array}{c}\begin{array}{c}\text { Soluble } \\
\text { solids } \\
\text { concn }\end{array} \\
\end{array}$ \\
\hline$\overline{\sigma_{g}^{2}}$ & $3.28(82.0 \%)$ & $7.50(494 \%)$ & $0.48(10.6 \%)$ \\
\hline$\sigma_{\mathrm{g}}^{2}$ & $0.01(0.3 \%)$ & $1.55(10.2 \%)$ & $1.13(24.9 \%)$ \\
\hline$\sigma_{\mathrm{y}}^{2}$ & $0.07(1.8 \%)$ & $1.39(9.2 \%)$ & $0.99(21.9 \%)$ \\
\hline$\sigma_{t}^{2 y}$ & $0^{y}(0 \%)$ & $0.13(0.9 \%)$ & $0.06(1.3 \%)$ \\
\hline$\sigma_{t}^{2}$ & $0.15(3.7 \%)$ & $0.50(3.3 \%)$ & $0.17(3.8 \%)$ \\
\hline$\sigma_{t y}^{2}$ & $0.49(12.2 \%)$ & $4.10(27.0 \%)$ & $1.70(37.5 \%)$ \\
\hline$\sigma_{\mathrm{f}}^{2}$ & $4.00(100.0 \%)$ & $15.17(100.0 \%)$ & $4.53(100.0 \%)$ \\
\hline
\end{tabular}

${ }^{2}$ Fruit weight was logarithmically transformed.

${ }^{y}$ Negative-values were assumed to be zero.

the three components, ranging from $12.2 \%$ to $37.5 \%$. The $\sigma_{\mathrm{ty}}{ }^{2}$ was $\approx 3 \%$ to $4 \%$ of the total variance. The $\sigma_{\mathrm{gy}}{ }^{2}$ was as large as $\sigma_{\mathrm{y}}{ }^{2}$, large compared with $\sigma_{\mathrm{ty}}{ }^{2}$ for FW and SSC, but very small (smaller than $\sigma_{\mathrm{vy}}{ }^{2}$ ) for FRT.

Variance estimation with 9 years, 19 genotypes, and one tree. Nineteen genotypes, including the eight from the previous experiment, with a single tree per genotype were used in this experiment (Table 3). Fifteen fruit were taken from each tree and examined for the three fruit traits for 9 years from 1982 to 1990.

The mean values of each genotype and year were subjected to analysis of variance using the following model: $\mathrm{P}^{\prime}=\mu^{\prime}+\mathrm{g}_{\mathrm{i}}{ }^{+}+\mathrm{y}^{\prime}+$ $\mathrm{e}_{\mathrm{ij}}$, where $\mathrm{P}_{\mathrm{ij}}$ is the phenotypic value of the ith genotype in the jth year, $\mu$ ' is the overall mean, $\mathrm{g}_{\mathrm{i}}{ }_{\mathrm{i}}$ is a random effect of the ith genotype, $\mathrm{y}_{\mathrm{j}}$ is a random effect of the jth year, and $e_{i j}$ is the residual effect of ith genotype and jth year. We assumed that all random effects had means of zero and were independent of each other.

The total variance $\left(\sigma_{\mathrm{T}}^{2}\right)$ was divided into $\sigma_{g}^{2}, \sigma_{y}^{2}$, and residual $\left(\sigma_{\mathrm{e}}^{2}\right)$. According to the analysis of variance, the effects of genotype and year were significant $(P \leq 0.01)$ for all

Table 3. The 19 Japanese persimmon genotypes evaluated over 9 years.

\begin{tabular}{ll}
\hline \hline Genotype & \multicolumn{1}{c}{ Origin } \\
\hline F-2 & $F_{1}$ of Jirou x Okugosho \\
Fuyuu & Native cultivar in Japan \\
Hanagosho & Native cultivar in Japan \\
Ichikikeijirou $^{2}$ & Bud mutant of Jirou \\
Izu $^{2}$ & $F_{1}$ of Fuyuu x Okitsu-1 \\
Izushiohgosho & Native cultivar in Japan \\
Jirou $^{2}$ & Native cultivar in Japan \\
Maekawajirou & Bud mutant of Jirou \\
Matsumotow- & \\
$\quad$ & \\
asefuyuu & Bud mutant of Fuyuu \\
Okitsu-1 & $\mathrm{F}_{1}$ of Okugosho selfing \\
Okitsu-14 & $\mathrm{F}_{1}$ of Okugosho x Hanagosho \\
Okitsu-16 & $\mathrm{F}_{1}$ of Okugosho x Hanagosho \\
Okitsu-20 & $\mathrm{F}_{1}$ of Fukurogosho x Hanagosho \\
Okitsu-21 $^{2}$ & $\mathrm{~F}_{1}$ of Jirou x Tenjingosho \\
Okitsu-24 $^{2}$ & $\mathrm{~F}_{1}$ of Jirou x Okitsu-15 \\
Okitsu-25 $^{y}$ & $\mathrm{~F}_{1}$ of Fuyuu x F-2 \\
Okugosho $^{2}$ & Native cultivar in Japan \\
Suruga & $\mathrm{F}_{1}$ of Hanagosho x Okugosho \\
Tenjingosho & Native cultivar in Japan \\
\hline The
\end{tabular}

${ }^{2}$ The eight genotypes used in the previous analysis (Table 2) in which they were measured with threetree replicates for 2 years.

${ }^{y} \mathrm{~F}_{1}$ of Okugosho x Hanagosho.

three fruit traits (Table 4). Year-to-year variability was divided into $\sigma_{\mathrm{y}}^{2}$ and $\sigma_{\mathrm{e}}^{2}$. Estimates of variance components are listed in Table 5 . The ratio of $\sigma_{g}^{2}$, to the total variance was highest for FRT and lowest for SSC. The $\sigma_{y}^{2}$ was largest for FW and lowest for FRT.

The $\boldsymbol{\sigma}_{\mathrm{g}}^{2}$, was composed of among-tree variance and the true genetic variance $\left(\sigma_{g}^{2}\right)$, which was obtained by subtracting $\sigma_{t}^{2}$ (estimated in the previous analysis of variance using eight genotypes) from $\sigma_{\mathrm{g}}^{2}$.

The $\sigma_{\mathrm{e}}^{2}$, consisted $\boldsymbol{\sigma}_{\mathrm{ty}}^{\mathbf{2}}, \boldsymbol{\sigma}_{\mathrm{f}}^{2} / \mathbf{n}$ (where $\mathrm{n}$ is the number of fruit examined per year), and the true variance for the genotype $\times$ year interaction $\left(\sigma_{g \mathrm{gy}}{ }^{2}\right)$. "The $\boldsymbol{\sigma}_{\mathrm{gy}}{ }^{2}$ ": was obtained by subtracting $\sigma_{\mathrm{ty}}^{2^{2 y}}$ and $\sigma_{\mathrm{f}}^{2} / \mathrm{n}$ (estimated in the previous analysis) from $\sigma_{c}^{2}$.

Higher precision can be expected for $\sigma_{\mathrm{gy}}^{2}$ than $\sigma_{\mathrm{zy}}^{2}$ because there are more degrees of freedom for the former. The diverse environmental variance components were estimated using $\sigma_{\mathrm{gy}}^{2}$ as the genotype $\times$ year interaction variance (Table 6), which was as large as $\sigma_{\mathrm{ty}}^{2}$

Heritability. Heritability $\left(\mathrm{h}^{2}\right)$ would increase if the environmental variance components decreased, for example, by removing the year effect. The year effect can be estimatedby the yearly deviation in mean performance of many control genotypes that are measured every year (M. Yamada and Y. Ukai, unpublished data). In such a case, the environmental variance of the mean for the progenies con(yt) $+\sigma_{\mathrm{t}}^{2} / \mathrm{t}+\sigma_{\mathrm{f}}^{2} /(\mathrm{ytf})$ here $\quad \sigma_{\mathrm{E}}^{2}$ is the total environmental variance of mean performance years repeated, $t$ is the number of trees, and $f$ is the number of fruit per tree and year.

The $h^{2}$ estimates were obtained by the following relation: $h^{2}=$ $\sigma_{\mathrm{E}}^{2} /\left(\sigma_{\mathrm{G}}^{2}+\sigma_{\mathrm{E}}^{2}\right)$, where $\sigma_{\mathrm{E}}^{2}$ is the environmental variance and $\boldsymbol{\sigma}_{\mathrm{G}}^{2}$ is the per genotype for 9 years.

${ }^{2}$ Fruit weight was logarithmically transformed

** Significant at $P \leq 0.01$. cerned may be expressed as $\quad \sigma_{\mathrm{E}}^{2}=\sigma_{\mathrm{gy}}^{2} / \mathrm{y}+\sigma_{\mathrm{t}}^{2} /$ in the progeny concerned, $y$ is the number of

Table 5. Estimates ofvariance components obtained from the analysis of variance for Japanese persimmon fruit traits using 19 genotypes with a single tree per genotype for 9 years

\begin{tabular}{|c|c|c|c|}
\hline \multirow[b]{2}{*}{$\begin{array}{l}\text { Variance } \\
\text { components }\end{array}$} & \multicolumn{3}{|c|}{ Fruit trait (mean square) } \\
\hline & $\begin{array}{c}\text { Fruit } \\
\text { ripening } \\
\text { time }\end{array}$ & $\begin{array}{c}\text { Fruit } \\
w^{2} \\
\left(\times 10^{-3}\right)\end{array}$ & $\begin{array}{c}\text { Soluble } \\
\text { solids } \\
\text { concn }\end{array}$ \\
\hline Genotype $\left(\sigma^{2}\right)$ & 1.65 & 4.19 & 0.72 \\
\hline Year $\left(\sigma_{y^{2}}^{2}\right)$ & 0.03 & 0.57 & 025 \\
\hline Residual $\left(\sigma_{\mathrm{e}}^{2}\right)$ & 0.25 & 1.23 & 0.47 \\
\hline
\end{tabular}

'Fruit weight was logarithmically transformed.

Table 6. Estimates of variance components obtained from the analyses of variance using eight genotypes for 2 years and 19 genotypes for 9 years.

\begin{tabular}{lccc} 
& \multicolumn{3}{c}{ Fruit trait (mean square) } \\
\cline { 2 - 4 } Variance & $\begin{array}{c}\text { Fruit } \\
\text { ripening }\end{array}$ & $\begin{array}{c}\text { Fruit } \\
\mathrm{wt}^{\mathbf{2}} \\
\left(\times 10^{-3}\right)\end{array}$ & $\begin{array}{c}\text { Soluble } \\
\text { solids } \\
\text { concn }\end{array}$ \\
\hline$\sigma_{\mathrm{g}^{\prime \prime}}^{2 \mathrm{y}}$ & 1.65 & 4.06 & 0.66 \\
$\sigma_{\mathrm{gy}}^{2 \mathrm{x}}$ & 0.07 & 0.45 & 0.19 \\
$\sigma_{\mathrm{t}}^{2}$ & 0 & 0.13 & 0.06 \\
$\sigma_{\mathrm{ty}}^{2}$ & 0.15 & 0.50 & 0.17 \\
$\sigma_{\mathrm{f}}^{2}$ & 0.49 & 4.10 & 1.70
\end{tabular}

"Fruit weight was logarithmically transformed.

${ }^{\mathrm{y}} \sigma_{\mathrm{g},}{ }^{2}=\sigma_{\mathrm{g}}{ }^{2}-\sigma_{\mathrm{t}}^{2}$.

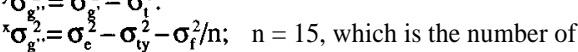
fruit examined per tree and year in the analysis for 19 genotypes measured for 9 years.

genetic variance of the progenies. Here, $\sigma_{\mathrm{G}}^{2}$ was replaced by $\sigma_{g \text {. }}^{2}$

Optimum repetition. The optimum number of tree replications and yearly repetitions to efficiently estimate genetic variability in breeding stocks can be calculated using values of environmental variance components (Table 6).

In breeding Japanese persimmon at the Akitsu Fruit Tree Research Station, top-graftmg techniques have been adopted to save space in the field and shorten the juvenile phase of trees. In this case, the number of replicates per seedling progenies to be topgrafted greatly influenced breeding efficiency. Here, $t$ is the number of trees top-grafted. During the second or third fruiting year, trees usually produced $\leq 10$ fruit when one progeny was top-grafted to a single branch of a mature tree. For trees to bear $\geq 20$ fruit in early fruiting years, top-grafting one progeny to two or more branches is required. The $\sigma_{\mathrm{E}}^{2}$ may be smaller when top-grafting to different trees than topgrafting to the same tree, since $\sigma_{\mathrm{t}}^{2} / \mathrm{yt}, \sigma_{\mathrm{t}}^{2} / \mathrm{t}$, and $\boldsymbol{\sigma}_{\mathrm{f}}^{2} / \mathbf{y t f}$ are expected to be smaller in the former Therefore, the repetition of $>10$ fruit per tree was not considered here.

Nineteen genotypes used in this experi-

Table 4. Analysis of variance for fruit traits of Japanese persimmon using 19 genotypes with a single tree

\begin{tabular}{lccccc}
\hline & & \multicolumn{3}{c}{ Fruit trait (mean square) } & \\
\cline { 3 - 6 } & & Fruit & Fruit & Soluble & Expected \\
Source of & & ripening & $\mathrm{wt}^{2}$ & solids & mean \\
variation & 18 & $15.07^{* *}$ & $38.90^{* *}$ & $6.92^{* *}$ & $\sigma_{\mathrm{e}}^{2}+9 \sigma_{\mathrm{g}}^{2}$ \\
Genotypc & 8 & $0.89^{* *}$ & $12.07^{* *}$ & $5.25^{* *}$ & $\sigma_{\mathrm{e}}^{2}+19 \sigma_{y^{2}}^{2}$ \\
Year & 144 & 0.25 & 1.23 & 0.46 & $\sigma_{\mathrm{e}}^{2}$ \\
Residual & & time & & &
\end{tabular}


ment were parents used in Japanese persimmon breeding programs. The $\sigma_{{ }_{6}}{ }^{2}$ was estimated from the $\sigma_{g}^{2}$, of 19 genotypes measured for 9 years, where the mean was 5.62 for FRT, $234 \mathrm{~g}$ for FW, and $17.39 \%$ for SSC.

The influence of spatial and temporal measurement repetition on $h^{2}$ is shown in Fig. 1. This figure can be used to assess the efficacy of the number of replicates or yearly repetitions for discriminating genotypes.

For FRT, $h^{2}$ was $0.84,0.90$, and 0.92 for the cases where single-tree, two-tree, and threetree replications, respectively, were used with five fruit without repeating years. Thus, $\mathrm{h}^{2}$ was estimated high, even in the case of a single tree with five fruit, without repeating years. Multiple measurements increased accuracy little for this trait. The $\mathrm{h}^{2}$ estimate was slightly higher for a single tree, five fruit, and 2 years than for two trees, five fruit, and a single year. The former was estimated as 0.91 and the latter as 0.90 . To increase $h^{2}$, an increase in the number of years instead of the number of tree replications was effective. We conclude that an increase in the number of fruit measured per tree and year increased accuracy little, because no clear difference in $h^{2}$ between 10 and five fruit was observed.

For FW, $\mathrm{h}^{2}$ was 0.68 in a case of a single tree, five fruit, and a single year. The $h^{2}$ increased to 0.85 by repeating the measurement for 3 years. The increase in accuracy by spatial and temporal measurement repetition was greater for FW than for FRT. Yearly repetition gave a larger increase in $\mathrm{h}^{2}$ than tree replication. The $\mathrm{h}^{2}$ was 0.77 for two trees, five fruit, and a single year, and was higher than for a single tree, five fruit, and a single year by 0.09-slightly lower than for a single tree, five

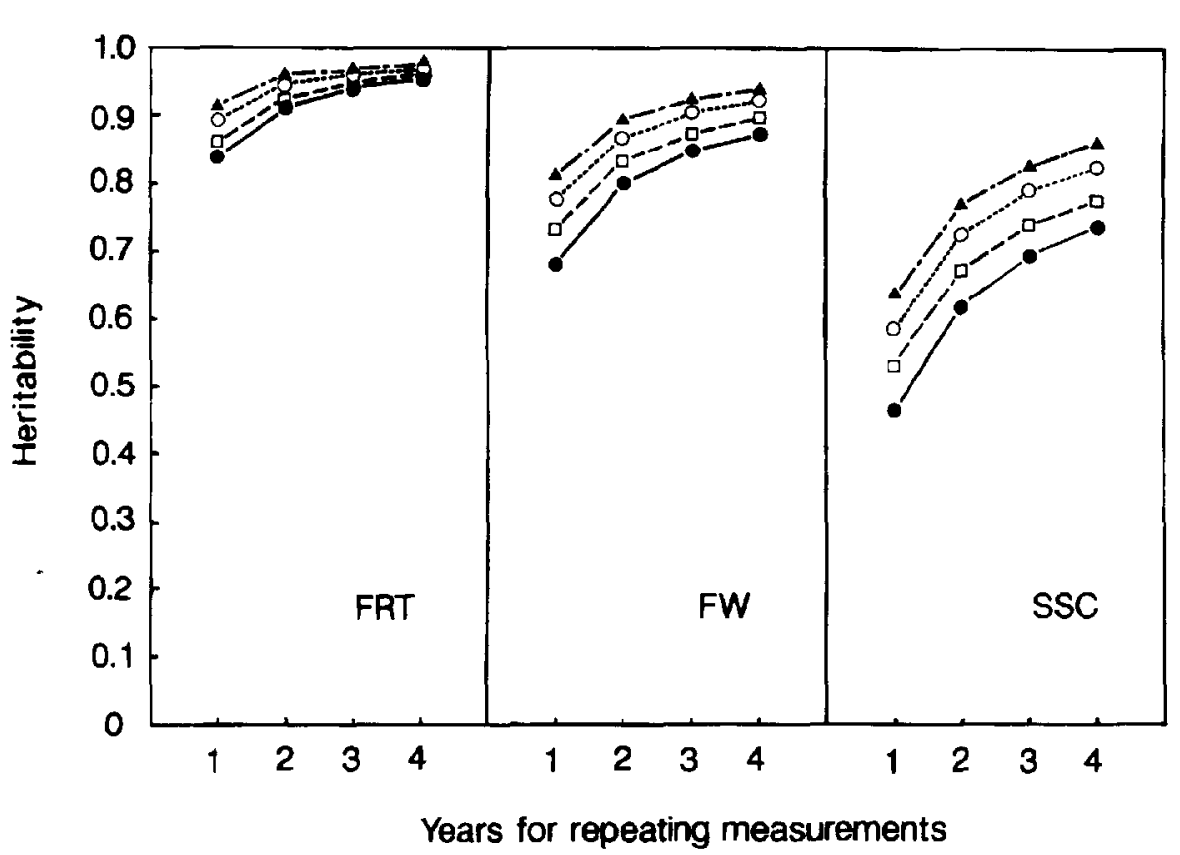

Fig. 1. Effects of tree replication, number of fruit, and yearly repetition for measurements on the heritability of fruit ripening time (FRT), fruit weight $(\mathrm{FW}$,$) and soluble solids concentration$ (SSC) of Japanese persimmon. Heritability was defined as $\sigma_{\mathrm{g}}^{2} /\left(\sigma_{\mathrm{g}}^{2},+\sigma_{\mathrm{g} y}^{2} / \mathrm{y}+\sigma_{\mathrm{ty}}^{2} / \mathrm{yt}+\sigma_{\mathrm{t}}^{2} / \mathrm{t}+\sigma_{\mathrm{f}}^{2} /\right.$ ytf) (see text for details). $\bigcirc=$ one tree and five fruit, $\square=$ one tree and 10 fruit, $\bigcirc=$ two trees and five fruit per tree, $\boldsymbol{\Delta}=$ three trees and five fruit per tree measurements and $t$ is the number of trees to be top-grafted, then the total number of branches top-grafted over years that can be accommodated $(T)$ is $T=N /[(3+y) \times t]$. For the cycle in which top-grafting was done to a single tree and the selection was done in the first year of fruiting and examination, $\mathrm{T}=\mathrm{N} /(4 \times 1)=\mathrm{N} / 4$. Similarly, with top-grafting to a single tree and selection in the third fruiting year, $\mathrm{T}=\mathrm{N} / 6$. However, when top-grafted to three branches on different interstocks and selection in the first fruiting year, $\mathrm{T}=\mathrm{N} /(4 \times 3)=\mathrm{N} / 12$.

Thus, an increase in the number of tree replications markedly reduced the total number of progenies that could be tested compared to an increase in years.

Conclusions. To compare the total number of progenies that can be field-tested, we have shown that using tree replications was less efficient than yearly repetitions. Unless $\sigma_{t}^{2}$ is markedly greater than $\bar{\sigma}_{\mathrm{gg}}^{2}$ it may be disadvantageous to increase the number of tree replications while sacrificing yearly repetitions. However, $\sigma_{t}^{2}$ was smaller than $\sigma^{2}$ for all fruit traits examined in the present study. An increase in yearly repetition instead of tree replications substantially reduced $\boldsymbol{\sigma}_{\mathrm{E}}^{2}$ in the measurements and, hence, increased $h^{2}$. This trend was pronounced for SSC and FW. In conclusion, field trials should be conducted over additional years rather than using more tree replications per year to maximize efficiency in Japanese persimmon breeding.

This conclusion is applicable mainly to first-stage selection on the total progeny population. Once a few genotypes have been selected, measurements should be obtained from many tree replications over many years to clarify the genetic properties of selected genotypes.

\section{Literature Cited}

Hansche, P.E. 1983. Response to selection, p. 154 171. In: J.N. Moore and J. Janick (eds.). Methods in fruit breeding. Purdue Univ. Press, West Lafayette, Ind.

Hansche, P.E. and V. Beres. 1966. An analysis of environmental variability in sweet cherry (Prunus avium L.). Proc. Amer. Soc. Hort. Sci. 88:173-183.

Hansche, P.E.and R.E. Brooks. 1965 Temporal and spatial repeatability of a series of quantitative characters in sweet cherry (Prunus avium L.) characters in sweet cherry (Prunus avium
Proc. Amer. Soc. Hort. Sci. 86:126-128. Proc. Amer. Soc. Hort. Sci. 86:126-128.
Hume, H.H. 1914. A kaki classification. J. Hered. Hume, H.H. 1914.
5:400-406.

Kaltsikes, P.J. 1970. Genotype-environment interaction variances in yield trials of fall rye. Can. J. Plant Sci. 50:77-80.

Machida, Y. and I. Kozaki. 1975. Quantitative studies on the fruit quality for Japanese pear (Pyrus serotina Rheder) breeding. I. Statistical analysis of cultivar populations. J. Jpn. Soc. Hort. Sci. 44:235-240.

Mycroft, H. 1983. Variability of yields in cereal variety $\times$ fungicide trials. J. Agr. Sci. 100:535538.

Patterson, H.D., V. Silvey, M. Talbot, and S.T.C. Weatherup. 1977. Variability of yields of cereal varieties in U.K. trials. J. Agr. Sci. 89:239-245.

Rasmussen, D.C. and J.W. Lambert. 1961. Variety $\mathrm{x}$ environment interactions in barley variety tests. Crop Sci. 1:261-262. 
Sekioka, T.T. and F.I. Lauer. 1970. Some estimates of genotype $\mathrm{x}$ environment interactions in potato variety tests. Amer. Potato J. 47:304-309.

Shorter, R. and R.J. Norman. 1983. Cultivar $\times$ environment interactions for kernel yield in Virginia type peanuts (Arachis hypogaea L.) in Queensland. Austral. J. Agr. Res. 3:415-426.

Swallow, W.H. and T.C. Wehner. 1989. Optimum allocation of plots to years, seasons, locations and replications, and its application to once-overharvest cucumber trials. Euphytica 43:59-68.

Yamada, M. and A. Kurihara. 1984. Studies on crossbreeding of Japanese persimmon (Diospyros kaki Thunb.). I. Repeatability of fruit characters in pollination constant non-astringent seedling population of Japanese persimm- on. Bul. Fruit Tree Res. Sta. Ser. E. 5:1-8.

Yamada, M., H. Yamane, and T. Hirabayashi. 1986. Studies on crossbreeding of Japanese persimmon (Diospyros kaki Thunb.). III. Genetical and environmental variation in population of pollination constant non-astringent varieties of Japanese persimmon. Bul. Fruit Tree Res. Sta. Ser. E. $6: 1-10$.. 